\title{
Transatlantica
}

Revue d'études américaines. American Studies Journal

\section{Paul Graham, American Night}

Galerie Les Filles du Calvaire, 17 rue des Filles du Calvaire, Paris $3^{\mathrm{e}}, 9$ sept. -28 oct. 2006

\section{Catherine Bernard}

\section{(2) OpenEdition}

1 Journals

Édition électronique

URL : http://journals.openedition.org/transatlantica/1165

DOI : 10.4000/transatlantica. 1165

ISSN : $1765-2766$

Éditeur

AFEA

\section{Référence électronique}

Catherine Bernard, «Paul Graham, American Night », Transatlantica [En ligne], 2 | 2006, mis en ligne le 22 décembre 2006, consulté le 29 avril 2021. URL : http://journals.openedition.org/transatlantica/ 1165 ; DOI : https://doi.org/10.4000/transatlantica.1165

Ce document a été généré automatiquement le 29 avril 2021

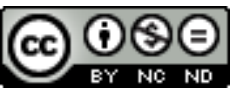

Transatlantica - Revue d'études américaines est mis à disposition selon les termes de la licence Creative Commons Attribution - Pas d'Utilisation Commerciale - Pas de Modification 4.0 International. 


\title{
Paul Graham, American Night
}

\author{
Galerie Les Filles du Calvaire, 17 rue des Filles du Calvaire, Paris $3^{\mathrm{e}}, 9$ \\ sept. -28 oct. 2006
}

\section{Catherine Bernard}

1 Le photographe britannique Paul Graham (1956-) ne jouit pas encore en France de la notoriété de son compatriote Martin Parr et on ne peut, par conséquent, que se féliciter de voir l'une de ses plus puissantes séries - American Night - représentée à la Galerie Les Filles du Calvaire.

2 Connu, avec Parr, pour avoir profondément influencé la photo documentaire anglaise en la faisant passer à la couleur avec virulence, Graham a été révélé il y a une vingtaine d'années par une série d'images prises à la sauvette dans les Job Centers de l'Angleterre de Margaret Thatcher. Tout à la fois témoignage à charge contre l'administration conservatrice et manifeste ethétique, Beyond Caring revendiquait la force dissidente de la couleur, à une époque où la photo documentaire se devait encore d'être en noir et blanc. Déjà, dans cette série, Graham élaborait un vocabulaire visuel par lequel toute l'économie de l'espace social était mise à nu. Refusant de recadrer des images prises à l'insu de l'administration, ces clichés d'une Angleterre à la dérive, se faisaient, dans leur déséquilibre même, allégoriques du déséquilibre collectif général. La série consacrée à l'Irlande du Nord (Troubled Land, 1987) devait confirmer l'art et la manière de Graham et en particulier sa capacité à lire un espace de manière allégorique, plaçant ainsi la photographie à la frontière du réalisme social et d'une herméneutique du politique.

C'est cette même attention aigüe aux modes de structuration de l'espace social qui sous-tend la série American Night dont la Galerie Les Filles du calvaire nous donne un saisissant échantillon. Le photographe braque cette fois son objectif sur la réalité de l'Amérique contemporaine, sur ses contrastes, et une forme de faillite du politique. L'entreprise pourrait sembler d'entrée cliché, n'était-ce la façon dont Graham parvient à renouveler les codes visuels de cette exploration de l'espace politique en faisant de ses clichés des œuvres à double détente, qui nous amènent aussi à nous réfléchir à leur surface, à réfléchir à la logique qui sous-tend notre propre captation visuelle du réel. 
Côte à côte, des images parfaitement impersonnelles, parfaitement connues, de l'Amérique prospère et des clichés, non moins monumentaux, de sans abris, de pauvres, isolés, perdus dans l'espace anarchique de conurbations anonymes, sans cesse différentes, toujours identiques. Côte à côte aussi, deux techniques qui se dévisagent sans communiquer : à la couleur saturée, parfaitement définie, plate, des clichés de l'Amérique prospère, bien connue des amateurs de la New Colour Photography, s'opposent des clichés laiteux, délibérement surexposés à la prise, les petits personnages perdus dans la ville étant à peine visibles derrière un voile opaque. Enfin, comme en contrepoint, sans qu'il y ait toutefois de synthèse : des clichés de SDF, pris dans une lumière rasante et profonde de fin d'après-midi, à ce moment où les choses et les êtres sont comme soudain lestés d'une présence pondéreuse.

Ces trois manières fonctionnent comme autant de modes de saisie allégorique de la réalité. À la platitude visuelle des riches demeures, devenues synecdoques d'un univers sans profondeur, déserté par la présence humaire, s'oppose la profondeur de champ des clichés neigeux, tous organisés autour d'une unique silhouette à partir de laquelle toute la construction du réel semble s'étalonner. À l'univers radieux de l'Amérique middle-class, à la perfection presque inquiétante de ses jardins et à l'impersonnalité de son architecture, s'oppose le chaos urbain des zones périurbaines. À la surexposition politique de l'Amérique qui gagne s'oppose une autre forme de surexposition, de nature technique celle-ci, qui complique la vision pour mieux surexposer ceux qui d'ordinaire sont sous-exposés par le discours dominant. Rarement la célèbre paire conceptuelle du studium et du punctum - autre cliché critique - n'aura semblé plus pertinente. À l'Amérique studieuse et plate, trop voyante, trop obvie, s'oppose une Amérique poignante, point de fuite autour duquel s'organise une mécanique de la relégation. C'est ce point aveugle, cet angle mort, soudain replacé au centre de la perspective, que Graham nous force à voir, à confronter frontalement, symétriquement, à notre place de spectateur rendu d'autant plus attentif que notre vision est empêchée, entravée par le voile laiteux créé par la surexposition.

Influencé de longue date par Walker Evans, Graham sait décaler le regard lassé de l'observateur. Il sait nous forcer à voir l'invisible. Admirateur de Bernd et Hilla Becher, il sait aussi lire les espaces intermédiaires, les zones en jachère de la modernité : carrefours informes, friches, espaces intersticiels, espaces de transit, comme jadis il sut regarder, scruter la profondeur de ces autres espaces de transit que constituaient les salles d'attente des Job Centers anglais, comme il sut aussi, dans son tout premier recueil, observer la vie en mouvement, la vie intermédiaire de la A I - la principale autoroute anglaise - dans A I. The Great North Road (1983).

7 Comme l'édition orginale de la série American Night le laisse entendre, qui se refuse à tout appareil critique ou pédagogique, à l'exception d'un extrait de L'aveuglement de José Saramago et d'un extrait de Moby Dick, tous deux imprimés blanc sur blanc et donc à peine lisibles, American Night est une leçon de vue, une leçon de vision. « On n'y voit rien ", serait-on tenté de dire avec Daniel Arasse, et pourtant, comme Arasse nous le rappelle, c'est peut-être à ce point d'aveuglement que commence une autre traversée de la surface du visible. 
INDEX

Thèmes : Trans'Arts 